\title{
O Estatuto da Criança e do Adolescente em DISCURSOS AUTORITÁRIOS
}

\author{
Flávia Cristina Silveira Lemos ${ }^{\star}$
}

\begin{abstract}
RESUMO
Pretende-se com este artigo interrogar a apropriação do Estatuto da Criança e do Adolescente, em práticas de poder e saber, acionadas por politicos populistas e autoritários logo após a promulgação deste código, por ocasião da inauguração do Ministério da Criança. Entre estes discursos, se encontra o do então Presidente do Brasil, no periodo, Fernando Collor de Mello. Através de uma metodologia histórico-genealógica de Michel Foucault e das contribuições teóricas da antropóloga Marilena Chaui, analisa-se os discursos que construíram as crianças e os jovens como a meta-síntese da Nova República brasileira. Estes atores idealizaram no Estatuto da Criança e dos Adolescentes o símbolo da entrada do Brasil na civilização e modernização, em uma concepção ilustrada da Lei como mecanismo de avanço e desenvolvimento de uma nação. Estas práticas tentavam apagar, por meio de jogos de poder, as lutas de movimentos sociais em prol da reivindicação de direitos de crianças e adolescentes.
\end{abstract}

Palavras-chave: democracia; Estatuto da Criança e do Adolescente; política autoritária; líderes populistas.

\section{The Statute of the Child and Adolescent in SPEECHES AUTHORITARIAN}

\begin{abstract}
It is with this article question the ownership of the Statute of the Child and Adolescent in power and know practices driven by populist policies and authoritarian soon after the promulgation of this code, at the inauguration of the Ministry of the Child. These speeches, is the then President of Brazil in the period, Fernando Collor de Mello. Through a historical and genealogical methodology of Michel Foucault and theoretical contributions of anthropologist Marilena Chaui, analyzes the speeches that built the children and young people as the goal-Brazilian synthesis of the New Republic. These actors idealized in the Statute of the Child and Adolescent symbol of the entry of Brazil in civilization and modernization, in an illustrated design of Law as a mechanism of progress

\footnotetext{
^Psicóloga; mestre em Psicologia e Sociedade; doutora em História; professora adjunta de Psicologia Social da Universidade Federal do Pará - UFPA. Endereço: Universidade Federal do Pará, Instituto de Filosofia e Ciências Humanas. Rua Augusto Corrêa, 01 - Guamá. CEP: 66075110 - Belém, PA - Brasil.

E-mail: flavialemos@ufpa.br
} 
and development of a nation. These practices they tried to delete, by means of games of be able, the struggles of movements socials in advantage from claim of rights of children and adolescents.

Keywords: democracy; Statute of the Child and Adolescent; authoritarian policy; populist leaders.

\section{INTRODUÇ̃̃o}

Após a promulgação da Constituição Federal, em 1988, com a inclusão dos artigos 227 e 228 fazendo referência aos direitos das crianças e dos jovens, acompanhamos uma mobilização de diversos grupos, movimentos sociais e instituições com o objetivo de criar uma nova legislação, em substituição ao Código de Menores de 1979, incorporando os princípios da Convenção Internacional dos Direitos da Criança (BOTELHO, 1993). Como resultado de intensas lutas e embates, sob a pressão de organismos internacionais e de movimentos sociais brasileiros, promulga-se o Estatuto da Criança e do Adolescente, em 1990.

O Estatuto, apelidado de ECA, foi assinado por Fernando Collor de Mello, primeiro presidente brasileiro eleito pelo voto direto, após a ruptura com a Ditadura Militar e a emergência de um processo de transição política para a democratização do país. Este Presidente disparou um conjunto de práticas referentes aos direitos de crianças e jovens tentando apagar ou deixar opaca a participação dos movimentos sociais na construção do ECA.

Deste modo, interroga-se, nas discussões abaixo a apropriação que Collor teria feito do Estatuto, ao tentar encarnar o lugar de líder doador de direitos às crianças e jovens do país. O Estatuto da Criança e do Adolescente tem sido alvo de intensos debates e completados seus 18 anos de existência no panorama jurídico-político brasileiro ainda não foi implementado efetivamente.

No panorama dos debates e dos documentos publicados sobre o ECA, analisamos um conjunto de discursos proferidos pelo então presidente Collor e por outros representantes do Poder Público por ocasião da promulgação do Estatuto, em julho de 1990. Problematiza-se a apropriação de uma das séries discursivas que compõe um amplo e polêmico debate, com diferentes lutas e jogos de poder.

Desta forma, apresentamos ao leitor uma análise problematizadora de um documento-monumento: "Brasil. Criança. Urgente: a Lei 8069/90" (COSTA et al., 1990), publicado sob a forma de livro. Problematiza-se este documento enquanto um conjunto de discursos-acontecimentos informados por práticas políticas, sociais, econômicas e culturais que sustentam modos de pensar a proteção de crianças e adolescentes, no Brasil, no período de democratização do país.

Para efetuar nossa análise de práticas de poder, de subjetivação e discursivas da apropriação do ECA em discursos de políticos populistas e autoritários, utilizamos a metodologia histórico-genealógica foucaultiana, recortando uma série específica de documentos-acontecimentos frente uma complexa teia de práti- 
cas e séries discursivas múltiplas e heterogêneas sobre o dispositivo Estatuto da Criança e do Adolescente. O artigo está construído em uma análise metodológica baseada nas contribuições de Foucault e em discussões teóricas ancoradas nos estudos de Chauí, especificamente de seus textos a respeito da tradição autoritária ainda presente na realidade brasileira.

Pensar genealogicamente seria acionar uma análise interrogante, em um exercício constante de demolição das evidências. O método genealógico não se preocupa em identificar relações causais entre os acontecimentos, lhes oferecendo um sentido de continuidade, com uma origem primeira e uma evolução rumo ao progresso e melhoramento. O genealogista demora-se sobre os documentos que narram o cotidiano, os detalhes do que parece não ter história. Trata-se da "constituição de um saber histórico das lutas e a utilização deste saber nas táticas atuais" (FOUCAULT, 1979, p. 171). Foucault produziu um modo de fazer história serial e acontecimental por meio da realização de perguntas-problemas para os arquivos e documentos, buscando analisar os "dispositivos e pontos de ruptura, planos de discurso e falas singulares, estratégias de poder e focos de resistência" (REVEL, 2005, p. 59).

Para problematizar este processo de naturalização do objeto "proteção à criança e ao adolescente", foi utilizado um operador metodológico caro a Foucault (VEYNE, 1998) - o de "práticas". A prática é o fazer e, "o objeto, se explica pelo que foi o fazer em cada momento da história" (VEYNE, 1998, p. 257). Logo, as formas de assistir as crianças e os jovens seriam correlatas de práticas múltiplas e datadas.

Os arquivos são cruzamentos entre "mecanismos políticos e efeitos de discurso" (FOUCAULT, 2003[1977], p. 211). Para analisar as relações entre saberpoder, Foucault (1979, p. 244) criou a noção de "dispositivo", definindo-o como:

[...] um conjunto decididamente heterogêneo que engloba discursos, instituições, organizações arquitetônicas, decisões regulamentares, leis, medidas administrativas, enunciados científicos, proposições filosóficas, morais, filantrópicas.

As práticas discursivas são concebidas como instituições, pois têm uma realidade material e disparam efeitos, tais como: lutas, processos de servidão e dominação, jogos de palavras composto de perigos e de relações de poder, produção de saberes e difusão destes em espaços institucionais, captura das ações em regimes de força, domesticação da multiplicidade em arquivos e o estabelecimento de relações entre acontecimentos díspares (FOUCAULT, 2004).

Como desdobramento destas definições, poderíamos interrogar que táticas e estratégias foram agenciadas para a produção e apropriação de alguns documentos sobre o objeto atendimento de crianças e jovens, no Brasil, durante o período definido como redemocratização. Como foram produzidos estes documentos e de que modo ganharam visibilidade na cena pública e foram transformados em memória pelos brasileiros, na Nova República? 


\section{Crianças E Jovens CONSTituídos COMO Meta-síntese NACIONAL}

O prefácio do documento "Brasil. Criança. Urgente: a Lei 8069/90", de autoria de Costa e Rivera (1990) levanta alguns pontos sinalizadores de uma concepção da criança e do jovem como meta-síntese nacional e símbolo do progresso de uma suposta consciência nacional, no início do governo Collor. A lei seria o dispositivo que nos conduziria à entrada na civilização e à saída da barbárie (BOTELHO, 1993). O Estatuto da Criança e do Adolescente seria classificado como resultado de uma verdadeira mutação e revolução social, jurídica e política do país, de acordo com a opinião dos dois autores.

No Capítulo I transcrevemos dois discursos que revelam o grande avanço da consciência nacional nesta área. [...] O Capítulo 2 transcreve: (a) um artigo profético em defesa da causa da criança à condição de meta-síntese da nova Administração Federal; (b) a seminal Carta à Nação Brasileira, do Congresso da Frente Nacional de Defesa dos Direitos da Criança (FNDdC), realizado em outubro de 1986, antes portanto da eleição da Assembléia Nacional Constituinte; (c) os textos constitucionais consagradores do novo direito propugnado na Carta. [...] O Capítulo seguinte apresenta textos que ajudam a compreensão da grande mudança - verdadeira mutação - representada pelo Estatuto da Criança e do Adolescente: seus aspectos civilizatório, social, jurídico, judiciário e político administrativo em nível municipal [...]. (COSTA; RIVERA, 1990, p. 9).

A idéia de uma consciência nacional ligada a uma identidade nacional, a um povo como uma unidade, como uma transcendência idealizada e da pátria enquanto entidade substancializada é afirmada pelos autores que prefaciam este livro-documento. Estes discursos constroem uma visão política utilizando metáforas que remetem aos discursos autoritários dos líderes populistas doadores de direitos e profetas redentores da Nação (BOTELHO, 1993).

Neste projeto nacional, a criança seria a meta-síntese, a responsável por apagar todas as diferenças políticas, econômicas, sociais, culturais, regionais, de classe, de etnia, de gênero em prol da construção de um ideal de unidade em busca do progresso e do desenvolvimento. A justiça estaria na base do progresso, de uma evolução linear de um "estado de natureza" para um "estado de razão". A razão iluminada se revelaria no formato de um pacto social simbolizado pela lei, nos conduzindo à modernização. O quadro jurídico-legal fundamentado na promulgação de uma Constituição Democrática, em 1988 e, em seguida, com a aprovação do Estatuto da Criança e do Adolescente, em 1990 seriam os dispositivos legais que nos fariam adentrar ao mundo dos países considerados civilizados (BOTELHO, 1993). 
A mudança jurídica se tornou o símbolo da mutação de uma realidade exaltada por Costa e Rivera (1990) no recorte do documento citado, acima. Para estes líderes populistas, a nova Carta, a Constituição de 1988, baniria os resquícios do autoritarismo e das práticas arbitrárias do Regime Militar e seria o mecanismo de ruptura com a Ditadura. O discurso de Collor, pronunciado em 31 de maio de 1990, por ocasião da inauguração do Ministério da Criança, ilustra a democracia como uma planta crescendo e florescendo. Em breve, a democracia iria frutificar e amadurecer como resultado do mandato de Collor e das ações de um povo que ele qualifica de abnegado e que acabara de acordar de um sono profundo.

Temos de dizer basta! Não podemos continuar a ser o Brasil das carências inaceitáveis e desumanas que afetam nossas crianças. [...] A democracia só floresce e frutifica numa sociedade em que as virtudes cívicas são cultivadas. [...] A democracia é também o universo das responsabilidades compartilhadas, e não haverá responsabilidade mais nobre, e mais clara expressão do bem comum, que a redenção de nossos menores. A proposta que agora faço é a de libertá-los, de uma vez por todas, das formas de violência e abandono (MELLO, 1990, p. 12-13).

Collor de Mello (1990) se apresenta como o líder que irá libertar os "menores carentes", convidando a nação a compartilhar com ele desta "missão", que ele designa como nobre. Neste ato, há uma evidente despolitização e apagamento das ações de grupos de reivindicação e de movimentos sociais que lutaram para a inserção de crianças e adolescentes em um quadro jurídico de cidadãos e de sujeitos de direitos (BOTELHO, 1993).

Chauí (1986) destaca que é comum em sociedades autoritárias a atribuição das transformações sociais, políticas, econômicas e jurídicas à ação de um líder autoritário, messiânico e que despertará a nação, conscientizando-a, integrando-a, conciliando-a e controlando-a. Os discursos de Collor podem ser enquadrados aos de um líder populista e autoritário, assumindo um caráter personalista, diluindo os conflitos sociais, em especial, os de classe em nome da união de um povo solidário e irmanado em busca da integração e desenvolvimento da nação. A infância seria causa de produção de um consenso movido por instintos biológicos e naturais. A democracia é concebida como metáfora da natureza (BOTELHO, 1993).

Em cada criança, em cada menor carente, há de se criar um brasileiro que tenha condições perfeitas para o exercício da mais autêntica liberdade. Vamos enfrentar o problema com determinação, com energia. Até hoje, pouco se fez. As iniciativas empreendidas foram sempre pequenas e inexpressivas diante da magnitude do drama. [...] Por isso estou convocando a Nação, cada brasileiro a engajar-se de corpo e alma na luta pela criança. Precisamos de todos: do cidadão, das famílias, das igrejas e organizações religiosas, dos empresários, dos trabalhadores, dos partidos políticos, 
dos organismos representativos da sociedade, dos veículos de comunicação. O Brasil, enfim, tem de conscientizarse de que ou salvam-se as crianças, ou perde-se o País. A luta pelo bem-estar e pela felicidade de nossos filhos tem a motivá-la o instinto natural mais profundo de defesa da prole e o imperativo ético maior da defesa do homem. De hoje em diante, a minha equipe de governo irá dedicar-se ao resgate das crianças brasileiras. [...] Que o dia de hoje marque o compromisso de meu governo com essa causa (MELLO, 1990, p. 13-14).

Collor infantiliza as crianças e os jovens usando termos, como carente e menor. Então, convoca a nação para contemplar como as crianças e adolescentes foram destituídos de direitos e seriam como filhos a serem guiados e restaurados de uma condição de escravidão, sendo libertos desta situação por ele, que passa a ocupar o lugar de salvador e redentor. Como líder populista e paternalista, ele convida a nação a se mobilizar de forma sentimental pela causa da infância a ser defendida por uma grande irmandade. Foucault (1979), em texto sobre a governamentalidade, ressalta como a gestão das populações se torna uma razão política amparada em uma lógica do pastor que cuida de um rebanho submisso e infantilizado.

Governar um Estado significará, portanto estabelecer a economia ao nível geral do Estado, isto é, ter em relação aos habitantes, às riquezas, aos comportamentos individuais e coletivos, uma forma de vigilância, de controle tão atenta quanto a do pai de uma família. (FOUCAULT, 1979, p. 281).

Ainda Foucault (1979), ao discutir a teoria da história em Nietzsche, interroga as categorias unificadoras, como a de "nação", usada por Collor para aglutinar em homogeneidade o que seria heterogêneo. O conceito de nação remeteria a uma identidade substancializada e, na genealogia foucaultiana, não há um rosto comum que uniria os corpos, como de uma identidade primeira ou uma essência original. Foucault (1979) explica como a categoria de origem remete à idéia de um tronco comum, de uma herança transmitida. O autor critica, em sua genealogia, a visão de origem como algo em comum em um grupo, ligando os indivíduos em uma identidade primeira ou por semelhança.

Chauí (1986) também ressalta que em sociedades autoritárias, se utiliza a concepção da importância da "unidade da família" e a "substancialização da nação" como modos de governar para pacificar as relações sociais. A busca do consenso se torna a forma de combate à existência de um suposto caos e crise social temida. A transição democrática parece ter sido gerida de forma prussiana, com a utilização de uma racionalização e reordenação autoritária empreendida por líderes que encarnaram o lugar de salvadores dos "carentes" e "menores". Apesar da mudança de regime, prevalece uma cultura política autoritária onde "os direitos são sempre apresentados como concessão e outorga feita pelo Estado, dependendo da vontade pessoal ou do arbítrio do governante." (CHAUÍ, 1986, p. 54). 
Collor (1990) ressalta a idéia de desenvolvimento como justiça social, como progresso humanitário. Ele evoca a necessidade de doação de parte do que ele nomeia como frutos do progresso com aqueles que estão em condição de abandono e violência, que ele qualifica como uma legião. A concepção nacional-desenvolvimentista dos anos 40-50 é apropriada por Collor que se posiciona como o governante que irá redimir a nação do atraso e da ignorância. De acordo com Collor, outros líderes afirmaram um modelo de desenvolvimento somente econômico e, o que ele solicita é uma atitude voluntarista da sociedade para gerir os resultados deste modelo político e econômico, destituindo o Estado desta responsabilidade, que no discurso do então presidente deveria ser compartilhada.

O sacrifício imposto pela reorganização da economia não pode de maneira alguma esgotar-se em si mesmo. Não é suficiente. A ação do Governo deve ter uma preponderante dimensão social e humanitária. Num país marcado ainda pela pobreza e pela injustiça na repartição dos frutos do progresso, o Governo precisa ser fonte de inspiração para uma profunda mudança de hábitos, atitudes e sensibilidades. Que nação é esta que não quer ver o drama social? Que nação é esta que insiste em não reconhecer a absoluta prioridade de acabar com o sofrimento de milhões e milhões de brasileiros? Não há desenvolvimento sem justiça social. A justiça social é requisito básico do desenvolvimento, da nacionalidade e da cidadania. [...] Herdamos os efeitos de um modelo de desenvolvimento em cujo nome, entre muitos erros e omissões, cometeu-se o desatino de deixar pelo caminho, abandonados nas cidades e nos campos, expostos à doença, à corrupção, ao crime e às drogas, uma verdadeira legião de menores carentes de tudo. (MELLO, 1990, p. 15-16)

A análise da proveniência em Foucault (1979) permite conjurar a quimera da origem, rompendo com as unidades e continuidades advindas de uma essência primeira a ser restaurada. Já, a análise da emergência permite conjurar a teleologia, a idéia de que há um futuro melhor em evolução, que há um progresso e retorno à unidade primeira perdida. O humanitarismo apresentado por Collor (1990) poderia ser problematizado pela lógica da análise da emergência, em que a busca de divisão dos frutos do progresso remeteria à visão de uma felicidade a alcançar, de um paraíso a instaurar, de uma evolução e desenvolvimento a chegar como telos, como um alvo a atingir, no porvir.

Collor demagogicamente convoca os brasileiros a trabalhar para a "recuperação" daqueles que ele concebe como em vias de marginalização, que estão destoando das expectativas de docilidade e produção, que estão ausentes das instituições de disciplina e controle como a escola e a família. Para tanto, ele afirma que irá se preocupar com a atenção à mãe, figura-chave do discurso positivista e médico-higienista de vigilância das crianças no interior da família. 
Temos o dever de reverter essa situação; de garantir alimentação e saúde para as nossas crianças. Temos de tirálas das ruas e dos desvios da marginalidade; de encaminhálas à escola motivando-as para o estudo. Temos de levá-las de volta ao seio da família, ao convívio e guarda de pais capazes de dar-lhes sustento, afeto e amor; de fazer prevalecer o sentido da paternidade responsável. Temos de recuperar de uma vez por todas a família brasileira. Atenção especial será dada às medidas que tenham por objetivo apoiar a mãe, tanto no período de gestação como na fase decisiva do aleitamento. A salvação da infância começa necessariamente por esse cuidado (MELLO, 1990, p. 15-17).

Foucault $(1979,1999)$ destaca como os discursos médico-higienistas vão sendo divulgados e apropriados politicamente, em defesa da sociedade, a partir da segunda metade do século XIX, como vetor de fortalecimento dos Estados Modernos. Nestas discussões, o autor relata que a infância se torna o alvo principal de atenção dos governantes e a família o segmento privilegiado de gestão das crianças. Opera-se uma medicalização da família e esta se torna uma agência medicalizadora da prole.

As práticas enunciadas por Collor funcionam como um convite aos brasileiros a cultivarem os valores que se fundamentem nos ideais de uma sociedade capitalista modernizada e que caminha para o progresso por meio da organização de reformas estruturais da economia brasileira, a partir de forças neoliberais, desmontando a assistência pública estatal e privatizando-a, como assinala Oliveira (2003).

Temos de estabelecer, em bases sólidas, valores que guiem a vida em sociedade. De que serve crescimento econômico se não há solidariedade entre os brasileiros? O projeto de uma grande nação se faz com valores que sejam escolhidos livremente por sua gente. Mas não existirá um país feliz se os seres mais débeis de sua sociedade são marginalizados, ou são esquecidos. [...] Assumo, a partir de agora, o desafio de liderar a Nação na obra de construir um Brasil novo para as crianças. Entro nessa batalha como Presidente da República, como brasileiro e, sobretudo, como pai. [...] Acredito e confio no Brasil. Este ainda há de ser lugar ideal para se viver. [...] Sabemos todos que o Brasil tem condições plenas para transformar-se numa grande potência (MELLO, 1990, p. 16-17).

Assim, apesar de Collor realizar promessas de salvação de modo populista e autoritário, tentando desfazer o jogo de relações de poder móvel e mutante que constitui as leis e as condições sociais e políticas, o que lhes confere historicidade, pode-se aprender com Foucault (1979, p. 26), através da análise da emergência, 
em que a história será "história das morais, dos ideais, dos conceitos metafísicos, história do conceito de liberdade ou da vida ascética, como emergências de interpretações diferentes." Foucault (1979, p. 25) lembra que:

[...] a humanidade não progride lentamente, de combate em combate, até uma reciprocidade universal, em que as regras substituiriam para sempre a guerra; ela instala cada uma de suas violências em um sistema de regras, e prossegue assim de dominação em dominação.

Em uníssono com o discurso do ex-presidente Fernando Collor de Mello, o cientista político Rivera (1990, p. 24-25), um dos organizadores do documento "Brasil, criança urgente: a Lei 8069/90" afirma que as crianças e os adolescentes seriam a meta-síntese do processo de reconstrução nacional:

Pois no naufrágio patente do nosso atual modelo de sociedade (com ilhas de modernidade, mas em verdade ainda arcaica, porque corporativa, cartorialista e cartelizada) temos jogado ao mar precisamente o nosso mais precioso tesouro. [...] Contudo, há momentos da vida dos povos em que a consciência do perigo é o melhor antídoto contra a epidemia da omissão e a insensatez da irresponsabilidade. É exatamente dessa consciência que nascem tanto a vontade social de pagar os custos da mudança como a decisão biofílica de priorizar o mais importante - aquilo que dá sentido à viagem - e de infletir rumos, corrigir erros, revisar mapas, redefinir metas, redobrar esforços. [...] Erigir a infância e a juventude como a meta-síntese do processo de reconstrução nacional que o novo Governo deseja desencadear significa muito mais que um compromisso ético ou uma intuição profética: representará uma decisão política de alto poder mobilizador e simbólico, profundamente ancorada no único imperativo constitucional de absoluta prioridade.

Ora, se já apontamos como Foucault (1979) interroga a unidade substancializadora, na análise genealógica da proveniência, então não há meta-síntese restaurativa e reconstrutora da "nação" como deseja fazer crer e evoca Rivera (1990). Como salienta Foucault (1979, p. 20) "não se trata de modo algum de reencontrar em um indivíduo, em uma idéia ou um sentimento as características gerais que permitem assimilá-los a outros - e de dizer: isto é grego ou isto é inglês [...]". Assim, não há essência brasileira a unificar os brasileiros em uma identidade nacional e sim, multiplicidades de acontecimentos em transformação sem unidade e sem meta-síntese.

Deodato compara o Estado e a Nação a uma família que instintivamente protegeria sua prole em situações perigosas, entregando a própria vida pelos filhos, assim, também seria salva a Nação, sob a liderança do Presidente da República e pelos demais representantes do governo, dispostos a se sacrificar pelos 
brasileiros. A nação aceitaria pacificamente sacrificar-se para que crianças e jovens fossem priorizados na agenda política. Fabrica-se um "nós" desprovido de história e essencializado na identidade nacional de modo autoritário e populista.

Trata-se não só de um "amor natural” aos filhos, mas de uma política preventiva, pois Rivera (1990) declara que salvar as crianças e a juventude é um modo de gestão pública que evitaria perigos e promoveria o desenvolvimento modernizador. Foucault (1979), analisando as formas de governo, destaca que a gestão da população se tornou uma prerrogativa de um Estado que elegeu a economia política como sua mola propulsora de desenvolvimento e força. Governar a população seria gerir os perigos a que estaria submetida ou em vias de.

Com essa decisão estratégica o novo Governo estará emitindo um sinal subliminarmente dinamizador, no nível do inconsciente coletivo (onde, aliás, a vontade e a fé se misturam e se argamassam reciprocamente), que será um chamado poderoso e irresistível àquela corrente submersa no recôndito da alma nacional - fonte de solidariedades, criatividades e heroísmos que só os grandes líderes sabem intuir e canalizar - sem a qual nenhuma nação se levanta depois de uma derrota, uma catástrofe, um dilaceramento interno ou um desastroso e persistente equívoco de rota, capitão e timão no trato com a coisa pública. Assim como em qualquer família o sacrifício em benefício dos filhos é aceito em geral com um misto de orgulho e coragem, a definição das nossas crianças e jovens como meta-síntese, a ser escrupulosamente posta a salvo das ameaças da travessia reconstrutora, despertará as energias insuspeitadas do nosso povo. [...] No início da segunda metade deste século, a metasíntese que sinergizou a Nação e assombrou o Mundo se chamou Brasília. Sob o signo da Esperança e a condução do Arrojo, o sonho de um santo-profeta se transformou em cidade (RIVERA, 1990, p. 25).

As crianças e os adolescentes seriam salvos pelo líder messiânico em seu ato profético, o Presidente Fernando Collor de Mello, qualificado como pai de todas elas por Rivera (1990). Todos os movimentos sociais que lutaram pela mudança no panorama legal e para a instauração das crianças e dos jovens como sujeitos de direitos são apagados por um discurso populista e biologizante que naturaliza a ação política e a transforma em símbolo de paternidade instintiva.

Para o cientista político Rivera (1990), o Estatuto da Criança e do adolescente é uma lei civilizatória, comparada à Lei Áurea. Ambas teriam retirado o Brasil do campo da barbárie. O Estatuto foi aprovado em 1990, no mandato do Presidente Fernando Collor de Mello, sem vetos. No entanto, o ECA representa o resultado de lutas e embates de forças que se imbricaram em uma rede de relações, de demandas e de reivindicações anteriores à posse do Presidente Fernando Collor. Portanto, se Collor tenta se apropriar deste documento como doação, 
pretende-se, neste artigo, desconstruir e romper com esta prática, assinalando um contexto anterior de ações articuladas dos movimentos sociais que não podem ser esquecidas pela opacidade política de cunho autoritário.

Conforme Gomes (1982), uma das marcas das ações autoritárias é a tentativa de apagar a historicidade dos objetos ou de ver a história como uma linha do tempo, em uma continuidade evolutiva em direção ao progresso. A história como evolução linear seria a marca de uma teleologia e de uma cultura política autoritária. Deste modo, se não podemos deixar de negar as rupturas e garantias previstas no Estatuto da Criança e do Adolescente, também não podemos torná-lo o ápice da história das políticas de proteção e atenção voltada para as crianças e jovens, sob pena de fazermos uma história linear, evolutiva e contínua.

É fundamental assinalar que a aprovação do ECA não pode ser compreendida como o resultado da ilustração política doadora de direitos, como queriam Collor e Deodato. É importante observar que uma cultura política autoritária constrói-se em um amálgama entre ordem e revolução, inovação e tradição, como aponta Gomes (1982). Defendemos a historicização do ECA, de suas rupturas frente aos códigos de menores e a análise genealógica do Estatuto a partir dos modos de organização social, política, cultural, econômica e de subjetivação que este agencia e produz como efeitos.

É preciso problematizar a visão de criança e jovens como meta-síntese ou como semióforo da "nação". Chauí (2000, p. 11-14) define semióforo "como um sinal ou signo unificador, de celebração da união de todos, integrador da sociedade, cultuado como núcleo de aglutinação de uma nação una e indivisível". Neste sentido, a crítica de Chauí ao conceito de semióforo se assemelha a que Foucault (1979) faz a respeito da visão de origem primeira e de essência, em sua análise da proveniência.

Chauí (2000, p. 15) nos ajuda a diferenciar os conceitos povo, nação e pátria, assinalando como o termo "nação" ganhou uma dimensão política. Já, o conceito de "pátria" vem do latim pater, pai em português, significando senhor, dono, proprietário. Logo, a "pátria" era algo que pertencia ao pai e estava sob o seu poder. De acordo com Chauí (2000, p. 16), após as revoluções francesa, americana e holandesa, o conceito de "pátria" é alterado, sendo definido como o território cujo dono é o povo ordenado através do Estado-nação independente:

Se acompanharmos a periodização proposta por Eric Hobsbawm, em seu estudo sobre a invenção histórica do Estado-nação, podemos datar o aparecimento de "nação" no vocabulário político na altura de 1830 , e seguir suas mudanças em três etapas: de 1830 a 1880, fala-se em "princípio da nacionalidade"; de 1880 a 1918, fala-se em "idéia nacional"; e de 1918 aos anos 1950-60, fala-se em "questão nacional". Nessa periodização, a primeira etapa vincula nação e território, a segunda a articula à língua, à religião, e à raça, e a terceira enfatiza a consciência nacional, definida por um conjunto de lealdades políticas. Na primeira 
etapa, o discurso da nacionalidade provém da economia política liberal; na segunda, dos intelectuais pequenoburgueses, particularmente alemães e italianos e, na terceira, emana principalmente dos partidos políticos e do Estado.

O nacionalismo teria prevalecido acima de todas as outras formas de luta, conforme Chauí (2000), na sociedade contemporânea. Pertencer à nação seria estar integrado por uma consciência nacional atrelada ao civismo e à política. Todas as diferenças se tornariam apagadas pela consciência nacional que uniria um povo, uma nação. Ela ainda afirma que, no Brasil, nos anos 1950-60, o nacionalismo é apresentado como o nacional-desenvolvimentismo seguido, depois, de um nacionalismo nacional-popular. No caso brasileiro, nos períodos de 1830 1880 e de $1880-1918$, houve um movimento nacionalista pautado pela idéia de caráter nacional, caráter entendido "como disposição natural de um povo e sua expressão cultural". A concepção de um caráter da nação é apresentada como algo pleno, seja positivo ou negativo, expressando "uma totalidade de traços coerente, fechada e sem lacunas porque constitui uma 'natureza humana' determinada" (CHAUÍ, 2000, p. 21).

Já, em outro momento, de 1918 a 1960, ganha centralidade uma concepção nacionalista de identidade nacional, que opera em outro registro. Este novo paradigma absorve a idéia de que a identidade deve ser concebida pelo que lhe seria externo, ou seja:

[...] não pode ser construída sem a diferença. O núcleo essencial é, no plano individual, a personalidade de alguém, e no plano social, o lugar ocupado na divisão do trabalho, a inserção social de classe. Isso traz como conseqüência que a 'identidade nacional' precisa ser concebida como harmonia e/ou tensão entre o plano individual e o social e também como harmonia e/ou tensão no interior do próprio social (CHAUÍ, 2000, p. 22-26).

O discurso de identidade nacional apresenta uma identidade delineada como uma totalidade lacunar, incompleta sob o signo da privação, do desvio, da falta e de uma consciência alienada. No Brasil, a imagem de completude e de uma totalidade de perfeição e acabada a qual nos comparamos é a dos países desenvolvidos. "É pela imagem do desenvolvimento completo do outro que a nossa 'identidade', definida como subdesenvolvida, surge como lacunar e feita de faltas e privações” (CHAUÍ, 2000, p. 27).

O retrato pintado do Brasil é o de uma nação portadora de uma identidade atrasada e bárbara que demanda uma "mutação civilizatória" para se tornar desenvolvida plenamente. As crianças e os adolescentes seriam o signo aglutinador desta empreitada, de acordo com os discursos populistas do ex-presidente Collor e de Rivera, que viram no Estatuto da Criança e do Adolescente o dispositivo de entrada no mundo da perfeição e da felicidade e nas crianças e jovens a metasíntese nacional. Nesta imagem idílica, todos os conflitos seriam apagados em 
prol da redenção das crianças e jovens, realizada pelos salvadores da pátria, os constituintes e por aquele que se nomeou pai dos brasileiros, Fernando Collor de Mello, em seu mandato de presidente da República.

Metáforas biológicas e cristãs misturam diagramas de nacionalismo-desenvolvimentista, nacionalismo-popular; caráter nacional e identidade nacional; em que crianças e jovens são proclamados sujeitos de direitos por outorga de um líder populista, um pai instigado por instintos biológicos. Esta atitude despolitiza o conceito de cidadania, pois, as crianças e jovens são apresentados como patrimônio da nação nos discursos destacados acima. Para os líderes populistas e autoritários, a harmonia seria produzida pelo consenso, a discórdia e contestação seriam vistas, para eles, como símbolo de perigo e deveriam ser eliminadas em nome da ordem e da paz.

\section{REFERÊNCIAS}

BOTELHO, R. U. Uma história da proteção à infância no Brasil: da questão do menor aos direitos da criança e do adolescente - 1920-1990. 1993. Dissertação (Mestrado)-Universidade de Brasília, Brasília, 1993.

BRASIL. Código de Menores. Lei no 6.697, de 10 de outubro de 1979. Disponível em: http://www.planalto.gov.br/ccivil_03/Leis/1970-1979/L6697.htm. Acesso em: 19 mar. 2009.

. Constituição (1988). Disponível em: http://www.planalto.gov.br/ccivil_ 03/Constituicao/Constitui\%C3\%A7ao.htm. Acesso em: 19 mar. 2009.

. Estatuto da Criança e do Adolescente. Lei no 8.069, de 13 de julho de 1990. Disponível em: http://www.planalto.gov.br/ccivil_03/Leis/L8069.htm. Acesso em: 19 mar. 2009.

COSTA, A. C. G. da; RIVERA, D. Introdução. In: COSTA, A. et al. (Org.). Brasil, criança urgente: a Lei 8069/90. São Paulo: Columbus, 1990. p. 9-10.

CHAUÍ, M. Conformismo e Resistência: aspectos da cultura popular no Brasil. São Paulo: Brasiliense, 1986.

. Brasil: mito fundador e sociedade autoritária. São Paulo: Fundação Perseu Abramo, 2000.

FOUCAULT, M. Microfísica do Poder. Rio de Janeiro: Graal, 1979.

.Em defesa da sociedade: Curso no Collége de France (1975-1976). 3. ed. São Paulo: Martins Fontes, 1999. 
FOUCAULT, M. A vida dos homens infames (1977). In: MOTTA, M. B. da (Org.). Estratégia, poder-saber. São Paulo: Forense Universitária, 2003. Coleção Ditos e Escritos, v. IV, p. 203-222.

. A ordem do discurso. São Paulo: Loyola, 2004.

GOMES, A. M. de C. O redescobrimento do Brasil. In: OLIVEIRA, L. L. (Org.). Estado Novo. Rio de Janeiro: Zahar, 1982. p. 109-150.

MELlO, F. C. de. O Ministério da Criança. In: COSTA, A. et al. (Org.) Brasil, criança urgente: a Lei 8069/90. São Paulo: Columbus, 1990. p. 12-17.

OLIVEIRA, F. de. Política numa era de indeterminação: opacidade e reencantamento. In: SILVA, F. T. da; NAXARA, M. R. C.; CAMILOTTI, V. C. (Org.). República, Liberalismo, Cidadania. Piracicaba, SP: UNIMEP, 2003. v. 1, p. 191-217.

REVEL, J. Foucault: conceitos essenciais. São Carlos: Claraluz, 2005.

RIVERA, D. A meta-síntese. In: COSTA, A. et al. (Org.) Brasil, criança urgente: a Lei 8069/90. São Paulo: Columbus, 1990. p. 24-26.

VEYNE, P. Foucault revoluciona a história. In: história. 4. ed. Brasília/DF: UNB, 1998. p. 238-285. . Como se escreve a

Recebido em: dezembro de 2008 Aceito em: março de 2009 